\title{
Linguagem e tecnologia na formação de professores de língua
}

\section{Language end technology in training of language teachers}

\author{
Anair Valênia ${ }^{1}$
}

Recebido em: 14/10/2019
Aprovado em: 18/11/2019
Publicado em: 19/12/2019

RESUMO: Este artigo discute questões relevantes acerca de ações de letramentos que podem fazer parte das práticas pedagógicas dos professores dos cursos de Letras, especialmente tendo em vista a formação docente para o ensino de língua materna. A discussão baseia-se nas teorias dos letramentos, sobre as quais empreendemos um curto percurso histórico, focando no início do desenvolvimento desses conceitos no Brasil (LEMLE, 1995; SMOLKA, 2003; SOARES, 2002, 2006), avançando para as proposições teóricas sobre os multiletramentos, conforme Kalantzis e Cope $(2003,2006)$ e passando por questões referentes aos letramentos digitais (DUDENEY, HOCKLY, PEGRUM, 2016). Tomamos como objeto de análise uma proposta de Iniciação Científica desenvolvida por um aluno-pesquisador do curso de Letras, e apontamos, ao final, as principais conclusões que pudemos observar, tais como: a relevância da autonomia para a escrita de um gênero discursivo digital e a hibridização de elementos como interatividade e multissemioses, que acabaram se tornando constitutivos na obra produzida.

Palavras-chave: Multiletramentos; Hiperconto; Interatividade; Multissemiose.

ABSTRACT: This article discusses relevant questions about literacy actions that may be part of the pedagogical practices of teachers of the Letras courses, especially with a view to the teachers training for the teaching of mother language. The discussion is based on the theory of literacies, in which we take a brief historical trajectory on the development of this concept in Brazil (LEMLE, 1995; SMOLKA, 2003; SOARES, $2002,2006)$, the multiliteracy, according to Kalantzis and Cope $(2003,2006)$ and through questions related to digital literacy (DUDENY, HOCKLY, PEGRUM, 2016). The purpose of this paper is to present a proposal of a Scientific Initiation developed by a student-researcher of the Letras course and we point out the main conclusions we could observe, such as: the relevance of autonomy for writing a digital discursive genre and the hybridization of elements such as interactivity and multisemioses, which eventually became constitutive of the work produced.

Keywords: Multiliteracy; Hypertale; Interactivity; Multisemioses.

1. Graduação em Letras Licenciatura Em Português Inglês E Respecti. Especialização em Lingüística Aplicada Ao Ensino da Língua Materna. Especialização em Pedagogia Empresarial e Recursos Humanos. Especialização em Tecnologias Digitais Aplicadas a Educação. Mestrado em Lingüística e Lingüística Aplicada. Doutorado em Lingüística Aplicada. Docente da Universidade Federal de Goiás no Programa de Pós-Graduação Estudos da Linguagem. ORCID: 0000-0002-8776-9124. E-mail: anair_valenia@hotmail.com 
VALENIA, A.

INTRODUÇÃO

Este artigo apresenta algumas discussões acerca da necessidade de se promover nos ambientes das universidades públicas do Brasil, ações de letramentos com e para os alunos de graduação, mais especificadamente aos alunos do Curso de Letras, visando a melhor prepará-los para a docência, para o ensino de Língua Portuguesa na contemporaneidade. Bhabha (2013) diz, ao refletir acerca de questões referentes a contemporaneidade, sobre o conceito de pós-modernidade, que o prefixo "pós" usado como um jargão para "indicar sequencialidade", que nossa vida é "marcada por uma tenebrosa sensação de sobrevivência, de viver nas fronteiras do 'presente', para as quais não parece haver nome próprio além do atual e controvertido deslizamento do prefixo 'pós': pósmodernismo, pós-colonialismo, pós-feminismo..." (BHABHA, 2013, p. 19, grifos do autor). Esse viver no e do presente, em nosso entendimento, no âmbito da universidade pública, é repensar a nossa prática a cada dia, tentando incorporar fazeres pedagógicos que atendam às expectativas dos discentes, especialmente no que diz respeito ao uso de recursos tecnológicos que podem ser empregados para mediar os processos de recepção e produção de textos em aulas de Língua Portuguesa. Ainda segundo Bhabha (2013, p. 24), "esses termos [pós-modernidade, pós-colonialidade, pós-feminismo] que apontam insistentemente para o além só poderão incorporar a energia inquieta e revisionária deste se transformarem o presente em um lugar expandido e ex-cêntrico de experiência e aquisição de poder", ou seja, é importante agir no presente, assegurando ponderações que nos possibilitem migrar de espaços de atitudes passivas para outros de ações empoderadas e autônomas.

Nesse sentido, apresentamos uma reflexão acerca dos resultados obtidos com uma investigação realizada no âmbito da Iniciação Científica (doravante IC), que buscou a promoção dos multiletramentos (em destaque os letramentos digitais) aos sujeitos envolvidos na proposta.

O percurso que seguiremos será o de apresentar uma discussão teórica sobre os letramentos e os multiletramentos para melhor entendermos o contexto no qual reside tal investigação e os letramentos requeridos pelas práticas sociais dos sujeitos em formação como pesquisador. Em seguida, apresentaremos o corpus e faremos a sua análise, recorrendo, quando necessário, a questões teóricas que subsidiaram a investigação de IC. 
VALENIA, A.

\section{Do letramento aos multiletramentos}

Giddens (1991), ao discutir sobre as descontinuidades que caracterizam e separam as instituições sociais modernas das ordens sociais tradicionais, o faz a partir da análise de três aspectos envolvidos nessa sistemática. A primeira descontinuidade diz respeito ao "ritmo de mudança nítido que a era da modernidade põe em movimento" (p. 15-16 - grifo do autor), ressaltando não a dinamicidade das mudanças empreendidas pelas civilizações tradicionais, mas a rapidez com que essas mudanças ocorrem na modernidade. A segunda característica se relaciona ao "escopo da mudança". Segundo o autor, à medida que há uma interligação entre os mais diversos espaços do planeta, as mudanças sociais se tornam imprescindíveis, penetrando virtualmente "toda a superfície da Terra". A terceira descontinuidade ocorre em relação à "natureza intrínseca das instituições modernas" (GIDDENS, 1991, p. 15-16), em que se observam transformações na forma de organização social contemporânea.

As posições teóricas aqui apresentadas desvelam uma nova ordem mundial tecnológica que requer novas formas de leitura e de escrita, que, por sua vez, requerem novos letramentos. A proposta, então, é debater sobre questões relacionadas a esses letramentos, partindo de um breve resgate histórico, passando pelo letramento digital até chegarmos aos multiletramentos.

Essas discussões são relevantes para compreendermos as práticas de letramentos que, até há pouco tempo, ocorriam nos espaços escolares (Educação Básica e Educação Superior) e que possuíam como cerne a linguagem escrita verbal como tecnologia para se ensinar a língua materna. Em contrapartida, o que temos hoje é a presença cada vez mais constante de textos que procuram harmonizar e produzir sentidos diversos com a utilização de diferentes semioses, como: áudio, links, animações, vídeos, imagens, cores, dentre outras. Além disso, esses textos multimodais e multissemióticos requerem novos letramentos e colocam novos desafios para as universidades, as escolas de Educação Básica e para os seus docentes.

Nesse sentido, faz-se relevante refletir sobre alguns dos letramentos que precisam ser abordados pelos espaços escolares e discuti-los ponderando acerca da rapidez com que as informações circulam e chegam até os discentes nesses tempos de globalização. Pensar também no acesso que esses alunos possuem aos aparatos tecnológicos digitais de comunicação e informação, tais como: smartphones, Ipods, câmeras digitais, celulares, playstations, tablets, e-readers, kindles etc. e na forma como esses aparelhos podem potencializar os processos de ensino e aprendizagem de língua. 
VALENIA, A.

A discussão sobre os letramentos no Brasil tem sido ampliada nos últimos anos, sobretudo quando se deslocou o status meramente escolar desse conceito para as implicações sociais, políticas e econômicas (BRAGA, RICARTE, 2005; KALANTZIS, COPE, 2006; MYERS, HAMMETTE MCKILLOP, 1998; ROJO, 2001; SOARES, 2006, 2002). Anteriormente às discussões sobre os letramentos, e em uma perspectiva social, falava-se sobre a necessidade de dar relevância à alfabetização por ser essa a fonte promotora do país às instâncias de primeiro mundo. Houve, então, por parte dos professores, uma preocupação em atender não só as demandas político-econômicas cobradas pelos órgãos superiores, como também tornar os alunos aptos a utilizarem a tecnologia da escrita a fim de que eles pudessem interagir nos mais diversos contextos situacionais em que estivessem inseridos.

Pensando historicamente sobre a alfabetização no Brasil, percebe-se que, especialmente na década de 1980, com os estudos de Emília Ferreiro sobre a psicogênese da língua escrita, a alfabetização deixa de ser entendida como mera apropriação de um código e passa a ser compreendida como um processo de representação linguística. No final da década de 90, destaca-se o trabalho de Miriam Lemle que aborda a alfabetização à luz da linguística. A partir dessa perspectiva, a autora organiza a questão da alfabetização em torno de alguns saberes e percepções. Primeiramente, a autora fala sobre a capacidade do educando de tentar compreender a ligação simbólica que há entre letras e sons da fala; depois, explicita sobre a habilidade de se perceber as distinções entre as letras e, por fim, sobre a "capacidade de ouvir e ter consciência dos sons da fala, com suas distinções relevantes na língua" (LEMLE, 1995, p. 10). Esse enfoque propõe que haja uma "consciência fonológica", que possibilite aos alfabetizandos refletirem sobre os sons da fala e agirem sobre eles.

Em um cotidiano em que professores e alunos ainda lutam para promover e adquirir, respectivamente, uma alfabetização "plena", e que, muitas vezes, nas palavras de Smolka (2003),

sobretudo no contexto escolar, produz constrangimentos. Desestabiliza. Questiona. Revela pressuposições e preconceitos na medida em que revela também (e documenta) a variedade nos modos de dizer. Variedade essa que, precisamente, des-cobre e manifesta os espaços de elaboração e os movimentos de transformação do discurso social (SMOLKA, 2003, p.80).

É nesse contexto que surge uma nova discussão sobre a dimensão sociocultural da aquisição da língua escrita e rompe com a visão reducionista de que a sala de aula é o único espaço de aprendizagem. Smolka defende a premissa de que, no processo de 
VALENIA, A.

alfabetização, devem estar engajadas atividades de leitura e de escrita como momentos discursivos, tendo em vista que, em sua essência, a alfabetização é constituída por discursividades, interlocução e interação.

Refletindo, então, nessa constituição discursiva da alfabetização, infere-se que as tecnologias da informação e da comunicação podem colaborar com as experiências de ensino e aprendizagem de maneiras diversas, tais como: propiciando momentos de maior interação, colaboração e cooperação entre os alunos, entre os alunos e os formadores e entre os alunos e os materiais pedagógicos disponibilizados no ambiente tecnológico; oferecendo ao professor e ao aluno uma alternativa para maior organização de seu trabalho e oportunidades para novas descobertas e, portanto, novas aprendizagens. Espera-se que essa ampliação dos ambientes tecnológicos propicie aos protagonistas da sala de aula oportunidades que possam conduzir a um trabalho que vá além do livro didático. Atividades que possibilitem aos alunos outras formas de obter conhecimento, como, participação em chats, realização de pesquisas diversas na rede www, participação em fóruns de discussão, criação e caracterização de avatares, dentre outras tarefas que possam promover os multiletramentos dos alunos.

Sobre o termo letramento, esse surgiu no Brasil na década de 1980 com Kato (1986). Desde então, muitos estudos e propostas têm surgido com o intuito de darem conta de discutir a dimensão conceitual desse termo, dentre os quais discutirei alguns a seguir.

Soares (2006), uma das primeiras pesquisadoras brasileiras a se debruçar sobre esse tema, explica o conceito de letramento partindo da etimologia da palavra Literacy-que vem do latim Littera (letra), dizendo que:

Literacy é o estado ou condição que assume aquele que aprende a ler e escrever. Implícita nesse conceito está a ideia de que a escrita traz consequências sociais, culturais, políticas, econômicas, cognitivas, linguísticas, quer para o grupo social em que seja introduzida, quer para o indivíduo que aprenda a usá-la. (SOARES, 2006, p.17).

Segundo a autora, espera-se que a escola seja capaz de conduzir os sujeitos para além de somente uma "aquisição da 'tecnologia' do ler e do escrever", mas que sejam capazes de usar essa leitura e essa escrita para processos de interação em práticas sociais do seu dia a dia. Observa-se que a perspectiva teórica assumida por Soares está fundamentada em uma dimensão social, em que letramento é "o que as pessoas fazem com as habilidades de leitura e de escrita, em um contexto específico, e como essas habilidades se relacionam com as necessidades, valores e práticas sociais" (SOARES, 2006, p.72, ênfase da autora). Nessa perspectiva teórica, há uma ampliação do conceito 
VALENIA, A.

de alfabetização em direção ao conceito de letramento: do saber ler e escrever em direção ao ser capaz de fazer uso da leitura e da escrita.

O efetivo uso da leitura e da escrita, especialmente na era contemporânea em que vivemos, com uma profusão de textos multissemióticos e multimodais circulantes, somados às ferramentas tecnológicas existentes, faz alguns estudiosos ampliarem as suas investigações e começarem a discutir sobre o letramento digital. Dentre esses pesquisadores, encontra-se Soares (2002) que, amplificando o seu conceito inicial de letramento, e analisando alguns dizeres de Pierry Lévy sobre o hipertexto, aborda alguns aspectos sobre o letramento digital explicitando que "é um certo estado ou condição que adquirem os que se apropriam da nova tecnologia digital e exercem práticas de leitura e de escrita na tela, diferente do estado ou condição - do letramento - dos que exercem práticas de leitura e de escrita no papel" (SOARES, 2002, p. 09 e 10). Segundo a autora, a leitura na tela requer dos leitores "novos processos cognitivos, novas formas de conhecimento, novas maneiras de ler e de escrever" (op. cit, p. 10), que podem, nos processos de interação, definir seus próprios percursos de leitura, acessar links e, de certa forma, interferir na estrutura e no sentido do texto. Essas reflexões acerca do letramento digital, que está associado às práticas sociais do uso do computador e da internet, ganharam maior visibilidade especialmente a partir da segunda metade da década de 1990.

Segundo Xavier (2009), o letramento digital implica mudanças na postura do sujeito em um momento de leitura e escrita em uma tela (que pode ser tanto uma tela de computador, quanto, por exemplo, a tela de um celular, a tela de uma televisão conectada a um playstation, a um notebook, a um bluray - que requerem conhecimentos específicos para lidar com cada um deles), mudanças "nos modos de ler e escrever os códigos e sinais verbais e não-verbais, como imagens e desenhos, se compararmos às formas de leitura $e$ escrita feitas no livro" (XAVIER, 2009. p. 02).

As imposições tecnológicas multimodais e multissemióticas da contemporaneidade motivam os estudiosos a explicarem quais seriam os letramentos requeridos para esses "novos" contextos sociais. Street (2003) aponta os "novos estudos do letramento" como uma fase em que a ordem é não considerar a "natureza da alfabetização" apenas dando relevância à "aquisição de competências, como em abordagens dominantes, mas sim sobre o que significa pensar alfabetização como uma prática social" (STREET, 2003, p. 01). Ao pensar nessa perspectiva, estaríamos frente aos "múltiplos letramentos" que, segundo o autor, variam "de acordo com o tempo e o espaço". 
VALENIA, A.

Em revisão à sua própria proposta de letramentos múltiplos, Street (2003, p. 01) reflete sobre a proposição, realizada por ele, de letramento no enfoque autônomo e no enfoque ideológico. Segundo o enfoque autônomo, o letramento ocorre de forma independente do contexto social, em "uma variável [...] cujas consequências para a sociedade e a cognição são derivadas de sua natureza intrínseca". Rojo (2009, p. 99), refletindo sobre essa dimensão do letramento, situa-o em âmbito escolar dizendo que "o contato [...] com a leitura e a escrita, pela própria natureza da escrita, faria com que o indivíduo aprendesse gradualmente habilidades que o levariam a estágios universais de desenvolvimento (níveis)". Já o enfoque ideológico, segundo Street (2003, p. 01), é entendido em sua relação com a cultura e o poder das pessoas envolvidas nas práticas sociais, portanto nas práticas de letramentos. Ainda segundo o autor, os novos letramentos ampliam os seus estudos e questionam a sua tese, sugerindo que a "prática de alfabetização varia de um contexto para outro e de uma cultura" para outra resultando, assim, em "diferentes letramentos em diferentes condições".

Trazendo as discussões sobre os letramentos para o contexto da escola, Rojo (2009) propõe que a educação linguística considere o aluno como um sujeito inserido em práticas sociais, dentro e fora do ambiente escolar, e que, por isso mesmo, possibilite a ele participar de diferentes eventos de letramentos: os multiletramentos ou letramentos múltiplos, os letramentos multissemióticos e os letramentos críticos e protagonistas. Os multiletramentos ou letramentos múltiplos devem ser referendados porque proporcionam aos alunos, professores e à comunidade escolar os enfrentamentos requeridos pelos "letramentos valorizados, universais e institucionais" sem, no entanto, desvalorizar os "letramentos das culturas locais" (ROJO, 2009, p.107) de cada sujeito envolvido nessas práticas.

Os letramentos multissemióticos são abordados a partir das exigências impostas pelos textos que circulam na contemporaneidade, que apresentam diversas semioses como vídeos, sons, imagens, textos, dentre outros. Em âmbito escolar, as práticas de letramentos tradicionais parecem não ser mais suficientes para dar conta de instrumentalizar o aluno para a produção e recepção de textos e hipertextos que se apresentam cada vez mais híbridos e multimodais,

a compreensão de que vivemos em um mundo multissemiótico (para além da letra, ou seja, um mundo de cores, sons, imagens e design que constroem significados em textos orais/escritos e hipertextos) e de que é necessário entender tal mundo, para que seja possível fazer escolhas entre os discursos que se apresentam, tem transformado a educação linguística em peça fundamental para enfrentar os desafios da contemporaneidade na 
VALENIA, A.

construção da cidadania (MOITA-LOPES; ROJO, 2004, p. 39, ênfase dos autores).

A compreensão do fato de que estamos vivendo em um mundo multissemiótico requer um letramento, também, multissemiótico, que acaba por nos impelir para a busca de uma "iniciativa cosmopolita" (SOUZA-SANTOS, 2005). Segundo Souza-Santos (2003, p. 01), o momento histórico que estamos vivendo pode ser classificado como de transição, pois o ritmo, a escola, a natureza e o alcance das transformações sociais são de tal ordem que os momentos de destruição e os momentos de criação se sucedem uns aos outros numa cadência frenética, sem deixar tempo nem espaço para momentos de estabilização e de consolidação.

Para acompanhar esse ritmo frenético, os sujeitos procuram, então, atender aos interesses sociais dos grupos nos quais estão inseridos em busca de uma emancipação social. Como resultado, há uma "mercadorização" (SOUZA-SANTOS, 2003, p. 56) de serviços como educação, saúde, habitação e segurança social que acabam por desestabilizar as relações entre os sujeitos. À educação fica, então, a tarefa de promover letramentos críticos e protagonistas que promovam o sujeito, se não a um status de transformador, ao menos a uma posição de entender criticamente os acontecimentos.

Os letramentos críticos e protagonistas são apresentados a partir de um tratamento "ético dos discursos em uma sociedade saturada de textos e que não pode lidar com eles de maneira instantânea, amorfa e alienada" (ROJO, 2009, p.108). Nesse sentido, segundo a autora, o aluno ao ser inserido em práticas de letramentos críticos tem a oportunidade de romper com essa relação amorfa com os textos historicamente construída e adquirir uma formação mais crítica no trato com a língua.

Myers, Hammett e McKillop (1998, p. 63), ao definirem o letramento crítico, o fazem a partir do que chamam de uma "subversão intencional de significado" em que há um confrontamento entre autores de textos diversos (com diversas semioses como imagens, músicas, vídeos, palavras) com o objetivo de se promover também significados diversos. Segundo os autores, quando inseridos em práticas de letramentos críticos, o autor/leitor compreende como os textos com os quais promove as suas interações significam sobre ele mesmo e sobre os outros. Nessas interações, o texto é "desalojado ou multiplicado em possiveis significados" (MYERS; HAMMETT e McKILLOP, 1998, p. 63-64) e transforma o leitor em espectador que sempre traz consigo muitos outros textos interligados para a sua produção de sentido, preparando-o para "ser e agir" em suas práticas sociais letradas. Um ambiente particularmente propício para se desenvolver essas práticas letradas é o de hipermídia, que permite as "representações de sequências múltiplas" (MYERS; HAMMETT 
VALENIA, A.

e McKILLOP, 1998, p. 63-64) de textos, gráficos, imagens, sons, dentre outros, que aparecem, às vezes, simultaneamente na tela do computador.

As mudanças nas práticas sociais, e que passam a exigir letramentos mais críticos, vêm atreladas à rapidez com que as informações invadem o nosso cotidiano e consequentemente a universidade. Os jovens estão, a cada dia, mais envolvidos com sites de relacionamentos; em interações em jogos que requerem a criação de avatares, como haboo, farmville, megacity, The Sims, Café Mania, jogos eletrônicos, e mesmo nas páginas de relacionamento com a criação de fakes ${ }^{1}$. Essa realidade é cada dia mais presente no cotidiano não só dos alunos como também de alguns professores que se veem rodeados por esse contexto virtual que exige letramentos mais críticos. O letramento crítico, portanto, incorpora uma série de aspectos relevantes para os sujeitos (MYERS, HAMMETT E MCKILLOP, 1998, p.69), tais como: exclusão e omissões, poder e privilégio, subjetividade, bem como emancipação de uma comunidade.

Sobre os multiletramentos, vamos encontrar as primeiras discussões empreendidas no New London Group (doravante NLG), para o qual o letramento acontece conforme a educação linguística contemporânea. Formado por pesquisadores de diversos países, o interesse maior do NLG é discutir e buscar entender principalmente "o que constitui um ensino de letramento apropriado no contexto dos fatores cada vez mais críticos de diversidade local e conectividade global" (KALANTZIS; COPE, 2003, p. 3).

Para pensar sobre os multiletramentos, o grupo justifica que, na contemporaneidade, há uma mudança na constituição dos sujeitos que hoje frequentam os ambientes escolares, bem como na ampliação dos canais e meios de comunicação. Essas mudanças e ampliações fazem com que todos estejam aqui e em todos os lugares ao mesmo tempo, bem como promovam o crescente aumento da diversidade linguística e cultural, que confrontam os sujeitos com uma grande diversidade textual que hoje circula na sociedade.

Ocorre que os alunos trazem consigo experiências diferentes de vida e, diante disso, "experimentam a educação de forma diferente e, consequentemente, seus resultados são diferentes" (KALANTZIS; COPE, 2006, p. 121). Os autores discutem, então, questões socioeconômicas relacionadas aos letramentos dizendo que, de uma maneira geral, as pessoas possuem uma melhor educação se forem mais ricas, falarem a língua nacional, pertencerem a grupos étnicos mais poderosos, forem homens, viverem em um bairro ou em uma cidade mais valorizados socialmente.

\footnotetext{
${ }^{1}$ Fake, que no inglês significa "falso", é usado na internet para denominar contas ou perfis daqueles usuários que querem ocultar a sua identidade real. Os fakes são encontrados nos diversos sites de relacionamento, em aplicativos e plataformas interativas.
}

Revista do SELL, Uberaba - V. 8 n. 2, p. 279-297, Jul./Dez. - 2019. 
VALENIA, A.

Segundo os autores, há "quatro formas arquetípicas" para a educação moderna: exclusão, assimilação, multiculturalismo e pluralismo, que se repetem de maneira uniforme e regular. Em relação à educação como exclusão, pode-se dizer que "na era moderna, quando a educação é obrigatória a promessa de igualdade através da educação é universal, a exclusão é uma poderosa forma de inclusão". É estar excluído de um contexto e incluído em outro, onde a "ausência é presença". Relacionada às questões do letramento, os autores apontam como sendo as "pedras de toque da exclusão" a visão restrita do letramento somada ao "discurso de poder ou competência" (KALANTZIS; COPE, 2006, p. 123) que circula na sociedade e nos ambientes escolares.

Tratando-se da educação como meio de assimilação, essa ocorre com o acesso à educação institucionalizada em que o sujeito obtém sucesso e constitui-se nos processos vivenciados. Quanto ao letramento, esse se efetiva quando um sujeito deixa o seu Lifeworld (mundo-da-vida) se deslocando para a cultura da educação. Segundo Kalantzis e Cope (2006, p. 123), ao atingir esse objetivo, o sujeito torna-se letrado "no sentido de ser uma encarnação viva da palavra oficial e do discurso do poder".

No âmbito da educação "como um tipo superficial de multiculturalismo", os autores chamam a atenção para o fato de que o letramento pode ocorrer ao serem oportunizados para os sujeitos momentos de leitura em que é possível adquirir conhecimento sobre as culturas de outras pessoas e desenvolver estratégias para, de alguma forma, ter acesso a elas. Nesse sentido, a prática de letramento só ocorre porque há uma "variabilidade do mundo da vida", embora o sujeito tenha que tentar se aproximar e se representar na imagem do mundo-da-vida que há na "cultura de aprendizagem institucionalizada e no poder dominante". No entanto, essa representação e essa aproximação do mundo-da-vida devem ser acomodações provisórias, somente enquanto "contribuem para a transformação em direção ao mundo-da-vida, a partir das margens para o centro" (KALANTZIS; COPE, 2006, p. 124).

No âmbito da educação como pluralismo, os autores defendem a ideia de que as oportunidades dos sujeitos não precisam ser semelhantes, mas sim "os mesmos tipos de oportunidades, medidas em termos de acesso aos recursos materiais, através do emprego, da participação política e do sentimento de pertencimento a uma comunidade mais ampla e localizada". Assim, a aprendizagem para esses autores não é o sujeito deixar para trás sua personalidade, seu mundo-da-vida, que é "moldada pela educação como mais ou menos inadequado para a tarefa da vida moderna" (KALANTZIS; COPE, 2006, p. 124), mas 
VALENIA, A.

sim o sujeito reconhecer a experiência do mundo-da-vida e usar essa experiência como base para a ampliação do que se sabe e o que se pode fazer.

Os pesquisadores do New London Group defendem, ainda, a ideia de que as diferenças de gênero, de cultura e de língua não devem impor dificuldades ou barreiras para uma educação adequada. Ao contrário dessa postura, o grupo defende que seja dada saliência a projetos que considerem as diferenças multiculturais existentes no alunado contemporâneo, dando visibilidade à dimensão profissional, à dimensão pessoal e à dimensão da participação cívica (KALANTZIS; COPE, 2006, p.125).

$\mathrm{Na}$ dimensão do mundo do trabalho, é defendida a posição de que os grupos reconhecem e utilizam a variedade irredutível e profunda das experiências do mundo-davida e estabelecem relações de complementaridade entre esses mundos. Em uma era de trabalho pós-fordista, espera-se um profissional que saiba se adaptar às mudanças constantes e aceitar as diferenças que a cada dia tornam-se maiores e mais marcantes. No âmbito da educação, é necessária uma pedagogia do pluralismo, em que se "conheça e aprenda sobre um mundo no qual a diversidade local e a proximidade global tornaram-se fatores de importância crítica" (KALANTZIS; COPE, 2006, p.130).

Na dimensão da participação cívica moderna, algumas mudanças são observadas, como a proliferação das escolas particulares - que oferecem todo tipo de promessas relacionadas ao mundo-da-vida; a retirada, por parte dos pais, dos seus filhos das escolas, realizando educação em casa; o aumento do marketing e da comercialização generalizada da educação. A principal consequência dessas atitudes, segundo os autores, é a dissolução da equidade. Assim, na era da "diversidade produtiva" e o "pluralismo cívico" as escolas devem ensinar novas competências e novas formas de moralidade cívica. Devem também "desenvolver nos alunos a capacidade de se envolverem em diálogos difíceis - que são partes inevitáveis de uma diversidade de negociação e desenvolver a moralidade do compromisso, em que ambas as partes da negociação estejam dispostas a ceder" (KALANTZIS; COPE, 2006, p. 139).

$\mathrm{Na}$ dimensão da vida pessoal, nos tempos modernos em que vivemos, ocorrem "mudanças mútuas nas esferas privadas e públicas, a partir da cultura de massa para a comunidade e identidades fragmentadas em várias camadas" (KALANTZIS; COPE, 2006, p. 140-141). A fim de explicitar melhor as mudanças ocorridas na vida pessoal, os autores apresentam alguns aspectos das mudanças na estética do consumo, nas relações de gênero e na linguagem. No universo do consumo, "a narrativa dos meios de comunicação cada vez mais estimula as pessoas em torno de uma identidade comum" (ibid, p. 140-141), 
VALENIA, A.

em que a cultura de massa é uma das consequências da produção e do consumo em massa. Nas relações de gênero, as principais mudanças observadas referem-se à família nuclear, em que o pai provedor sai para o mercado de trabalho, enquanto a mãe permanece cuidando da casa e das crianças; situação não mais vivida na contemporaneidade. As mudanças na linguagem, apontadas pelos autores, estão diretamente relacionadas à tentativa de reduzir a variedade linguística existente. Segundo eles, as consequências dessa postura é uma enorme queda do número de línguas em escala global e o aumento do número de pessoas e culturas que perderam suas línguas ancestrais de uma geração para a seguinte.

Com vistas a essa realidade que se apresenta na contemporaneidade, em que se observam mudanças nas mais diferentes esferas da vida, o NLG discute o fato de que é na escola que os sujeitos têm a oportunidade de ampliar os seus conhecimentos, rompendo as barreiras impostas pelas diferenças e pela rapidez com que as mudanças se processam. Essa ampliação das práticas de letramentos proporcionada pela escola deve partir do que, por exemplo, as universidades já realizam, ampliando as suas práticas para a efetivação de projetos que considerem, então, as três dimensões apresentadas acima: do trabalho, da cidadania e da vida pessoal.

Diante dessas discussões sobre os letramentos e multiletramentos, adotamos a proposta de multiletramentos como base para a realização deste estudo por considerá-la a teoria que melhor atende às expectativas em relação ao entendimento das práticas sociais e letradas do contexto investigado.

\section{O que nos propusemos a fazer...}

A preocupação com a promoção dos multiletramentos dos alunos de graduação e de pós-graduação é uma questão que sempre esteve presente em nossas atuações teóricopráticas e em nossas discussões. Frente à realidade que se apresenta na contemporaneidade, em que se observam mudanças nas mais diferentes esferas da vida, e tomando por referência a proposição de Kalantzis e Cope (2006) de que é na vida escolar que os sujeitos têm a oportunidade de ampliar os seus conhecimentos, rompendo as barreiras impostas pelas diferenças e pela rapidez com que as mudanças se processam, uma reflexão e investigação sobre os gêneros discursivos, no caso específico desta investigação, o gênero hiperconto, e os multiletramentos tornam-se relevantes.

Os resultados que apresentamos neste artigo são frutos dessas discussões e de uma submissão de IC que propusemos à Coordenação de Aperfeiçoamento de Pessoal de 
VALENIA, A.

Nível Superior-CAPES, que foi avaliada, aprovada e desenvolvida por um alunopesquisador do curso de graduação em Letras.

Segundo literatura corrente, dentre outros objetivos, a IC tem como propósito "estimular pesquisadores produtivos a envolverem alunos de graduação nas atividades científica, tecnológica e artística-cultural" e "proporcionar ao bolsista [...] a aprendizagem de técnicas e métodos de pesquisa, bem como estimular o desenvolvimento do pensar cientificamente e da criatividade" (BRASIL, 2015). Esses objetivos dialogam de forma bastante próxima às proposições dos multiletramentos aventadas por Kalantzis e Cope (2006), especialmente no que diz respeito ao comprometimento que as instituições de ensino devem ter em disponibilizar oportunidades semelhantes aos sujeitos envolvidos no ambiente escolar.

Neste artigo, em específico, nos deteremos na discussão acerca de uma submissão feita ao Programa Bolsas de Licenciatura-PROLICEN. A proposta (com período de efetivação de agosto de 2016 a agosto de 2017) teve como objetivo principal produzir um gênero hiperconto digital na plataforma gratuita www.wik.com, observando aspectos de interatividade requeridos pela obra e os elementos multissemióticos que são hibridizados em sua composição. É importante salientar que, em período anterior (agosto de 2015 a agosto de 2016), uma pesquisa de IC sobre o gênero discursivo digital hiperconto já havia sido desenvolvida, cujo objetivo principal foi investigar a constituição desse gênero, tomando como parâmetro a proposta de Bakhtin (2003 [1952-53/1979]) que o caracteriza conforme a sua estrutura composicional, o seu conteúdo temático e seu estilo. Ambas as proposições tomam a caracterização dos gêneros discursivos apresentada por Bakhtin (2003 [1952-53/1979]) como aporte teórico. Segundo o autor, ao se investigar um enunciado que se organiza em gêneros, é necessário observar três aspetos que lhe são constitutivos: a estrutura composicional, o conteúdo temático e o estilo. O conteúdo temático corresponde ao leque de temáticas que podem ser abordadas em um dado gênero. A estrutura composicional corresponde à macroestrutura interna do enunciado. $\mathrm{O}$ estilo, por sua vez, se relaciona aos recursos lexicais, fraseológicos e gramaticais utilizados pelo enunciador.

Entendemos, então, que a investigação poderia prosseguir e, dessa vez, salientamos a produção de um hiperconto, focalizando nas questões sobre gêneros, propostas por Bakhtin (2003 [1952-1953]); sobre interatividade, propostas por Hayles (2009) e sobre multissemioses, propostas por Rojo (2012, 2009), sem perder de vista as questões requeridas pelos multiletramentos. Além disso, aventamos que o hiperconto 
VALENIA, A.

produzido pode ser usado futuramente como objeto de ensino e aprendizagem na produção de planejamentos para o ensino de língua materna, tanto na educação superior quanto na educação básica.

\section{Os resultados que obtivemos...}

O projeto de pesquisa de IC-PROLICEN que orientamos, intitulado "O hiperconto como ferramenta de ensino e aprendizado da língua materna", como dito anteriormente, tinha como objetivo principal a criação de uma literatura eletrônica (HAYLES, 2009) que hibridizasse o maior número possível de semioses e que possibilitasse movimentos de interação entre o leitor e a obra. O objetivo principal da proposta foi promover os multiletramentos, capacitando o discente pesquisador para não somente a recepção do gênero discursivo digital hiperconto, mas também para a sua produção. Esse objetivo parece-nos foi alcançado, especialmente quando tomamos contato com os resultados da investigação ${ }^{2}$ e acessamos o hiperconto produzido ${ }^{3}$.

Além disso, outros aspectos positivos foram observados ao final da investigação. Dentre eles, destacamos a conceituação elaborada sobre o gênero discursivo digital hiperconto. Entendemos que conseguir conceituar o seu objeto de estudo não é uma tarefa muito simples, especialmente para alunos da graduação. Por outro lado, compreendemos que, para conseguir essa empreitada, o discente precisa estar de fato imerso em sua pesquisa, conhecer sobre o seu corpus, saber falar sobre ele e trazê-lo para fazer parte de suas reflexões e análises. Ou seja, é preciso que ele rompa com a postura passiva, que muitas vezes é imposta aos graduandos, para uma atitude responsiva ativa (BAKHTIN, 2003[1952-53/1979]) em que ele consegue produzir sentidos para o que está pesquisando. Dessa forma, partindo da teorização de Dias (2012), que defende que o gênero discursivo digital é uma,

estrutura multilinear, que além de ampliar a participação do leitor na produção de sentidos, convida-o a revisitar, ou a resgatar, a autonomia no processo de criação da tessitura textual e, ainda, a interagir com o hipertexto. Esse processo vai além da interação homem e máquina e é ampliada para a interação homem e conteúdo, homem e narrativa, homem e hipertexto. (DIAS, 2012, p. 102).

\footnotetext{
2 Disponíveis em https://iiiconpeex.catalao.ufg.br/up/957/o/mostra_prolicen.pdf?1508686015. Acesso em: 07 ago. 2019.

3 Disponível em http://santostainac.wixsite.com/enigma. Acesso em: 07 ago. 2019.
} 
VALENIA, A.

Desta forma foi possível então revisitar esse conceito, ampliando o mesmo no sentido de afirmar que é:

um gênero diferenciado do conto canônico, demarcado por recursos tecnológicos, característicos da era digital-tecnológica [...] hibridiza recursos tecnológicos multissemióticos, como hiperlinks, imagens e sons [...] uma vez que o suporte é outro, o meio é outro e os elementos da estrutura composicional são outros. [...] todos esses elementos formam uma estrutura composicional autêntica e diferente da estrutura do conto canônico. (SANTOS; DIAS, 2017, p. 1295).

Essa reflexão acerca do gênero em estudo nos leva a perceber que a proposta de IC capacitou o aluno-pesquisador para o desenvolvimento de uma conceituação acerca de seu próprio objeto de estudo. Ele foi capaz de migrar, como dito anteriormente, de uma atitude passiva para uma atitude "responsiva ativa", que parte do pressuposto de que "toda compreensão da fala viva, do enunciado vivo é de natureza ativamente responsiva (embora o grau desse ativismo seja bastante diverso); toda compreensão é prenhe de resposta, e nessa ou naquela forma a gera obrigatoriamente: o ouvinte se torna falante" (Bakhtin, 2003 [1952-53/1979], p. 271). Ao propiciar para o aluno de graduação a oportunidade para que ele possa realizar tal ponderação teórica, acreditamos que estamos contribuindo para a aquisição de uma autonomia intelectual, por meio da qual ele será capaz de entrar em contato com outras teorias, refletir sobre elas e, em seguida, produzir conhecimentos diversos.

Outro resultado interessante que obtivemos com a pesquisa foi a criação de um exemplar do gênero discursivo digital hiperconto, objetivo principal da investigação. A narrativa desenvolvida na obra apresenta como personagens os integrantes de uma família que se mudam para uma "cidade rural fictícia que tem como obscuro atrativo um labirinto antigo, construído por descendentes de egípcios e sobre o qual existem inúmeras histórias contadas pela vizinhança, entre elas a de um massacre ocorrido no passado" (SANTOS; DIAS, 2017, p. 1296-1297). Para construir essa narrativa e prender a atenção do leitor, o aluno-pesquisador procura hibridizar vários elementos multissemióticos à narrativa. Essa ação faz com que a obra (intitulada Enigma) torne-se repleta de elementos significativos e interessantes.

Rojo (2012) argumenta que o conceito de multiletramentos,

aponta para dois tipos específicos e importantes de multiplicidade presentes em nossas sociedades, principalmente urbanas, na contemporaneidade: a multiplicidade cultural das populações e a multiplicidade semiótica de constituição dos textos por meio dos quais ela se informa e se comunica. (ROJO, 2012, p. 13). 
VALENIA, A.

Ou seja, é preciso propiciar aos sujeitos conjunturas para vivências que hibridizam questões culturais e textos multissemióticos. Em "Enigma" constatamos uma multiplicidade de linguagens, tais como: uso de imagens diversas, como por exemplo a de um labirinto, que se torna extremamente significativo para o desenrolar da narrativa; hiperlinks, que conferem à obra uma interatividade constante, retirando o leitor de uma postura de mero receptor para a de coautor; recursos linguísticos, que criam um diálogo com o leitor, o conduzindo por percursos de decifração de enigmas, charadas e pegadinhas, interpelandoo para uma participação ativa na trama; utilização de diversos recursos sonoros, que ocorrem desde a "capa" da obra até o seu desfecho final, como por exemplo a música tema de Halloween (que por si só já cria uma atmosfera de suspense e terror); cores que remetem a um ambiente sombrio e aterrorizante.

Essas multissemioses presentes em "Enigma" nos levam a perceber que o alunopesquisador foi capaz de estruturar uma obra semelhante a diversos outros textos que circulam na contemporaneidade e que hibridizam várias semioses. Além disso, esse discente, que é interpelado a todo momento a ler não somente a linguagem verbal, mas a multiplicidade de signos que permeiam o seu cotidiano, mostrou-se letrado tanto para a recepção, quanto para a produção de um gênero discursivo digital interativo e multissemiótico.

\section{CONSIDERAÇÕES FINAIS}

Acreditamos que, com as ações desenvolvidas na proposta de IC, e efetivadas pelo aluno-pesquisador, estamos promovendo os multiletramentos, à semelhança do que é defendido por Kalantzis e Cope (2006), especialmente no que se refere ao âmbito da educação como pluralismo, ou seja, oportunizando vivências engajadas tecnologicamente, com participações emancipatórias intelectualmente. Outro fato relevante observado foi o desenvolvimento de sentimento de pertencimento à nova ordem tecnológica vigente, pois o discente pode conhecer, analisar e selecionar uma plataforma digital que propusesse as ferramentas multimidiáticas que atendessem às necessidades para a produção do hiperconto. Com essas ações de estudos e investigações em ambiente digital, foi possível promover os letramentos digitais que, segundo Dudeney, Hockly e Pegrum (2016), podem ser definidos como as "habilidades individuais e sociais necessárias para interpretar, administrar, compartilhar e criar sentido eficazmente no âmbito crescente dos canais de comunicação digital (DUDENEY, HOCKLY E PEGRUM, 2016, p. 17). 
VALENIA, A.

Nessa mesma perspectiva, a oportunidade de se criar um gênero discursivo digital oferecida ao aluno-pesquisador de IC, além de promover o seu letramento digital, o impele a situações não vivenciadas anteriormente, pois, muitas vezes, ele se encontra diante de práticas sociais em que precisa ir além da escrita da narrativa e se aventurar por vias de aplicativos e programas que possibilitam a criação de obras digitais multissemióticas e interativas.

Esse deslocamento do discente faz com que ele adquira autonomia para lidar com as ferramentas digitais, que só é possível quando se age sobre o aparato tecnológico, pois, quando se trata de ambiente digital, muitas dúvidas que surgem só podem ser sanadas quando se prossegue com o percurso traçado inicialmente e não se deixa desmotivar pelas dificuldades que surgem no itinerário de execução da empreitada. Além disso, todo o percurso de criação de uma literatura eletrônica propicia ao aluno-pesquisador não somente a aprendizagem por meio do enfrentamento das dificuldades, mas também de conquistas acadêmico-teóricas, pois ele torna-se capaz de produzir uma obra, cuja narrativa instigante e inédita, hibridiza diversas semioses e diversos processos interativos.

\section{REFERÊNCIAS}

BAKHTIN, M. M. Estética da criação verbal. Trad. de Paulo Bezerra. São Paulo: Martins Fontes, 2003 [1952-1953].

BHABHA, H. K. O local da cultura. Trad. de Myriam Ávila, Eliana Lourenço de Lima Reis, Gláucia Renate Gonçalves. Belo Horizonte: Editora UFMG, 2013.

BRAGA, D. B.; RICARTE, I. L. M. Letramento e tecnologia. São Paulo/Campinas: Cefiel, 2005.

DIAS, A. V. M. Hipercontos multissemióticos: para a promoção dos multiletramentos. In: ROJO, R.; MOURA, E. Multiletramentos na escola. São Paulo: Parábola Editorial, 2012, p. 95-122.

DUDENEY, G.; HOCKLY, N.; PEGRUM, M. Letramentos digitais. São Paulo: Parábola Editorial, 2016.

GIDDENS, A. As consequências da modernidade. Trad. de Raul Fiker. São Paulo: Editora UNESP, 1991.

HAYLES, K. Literatura eletrônica: novos horizontes para o literário. São Paulo, Global Editora, 2009. BRASIL. Universidade Federal de Goiás. Iniciação Científica. Goiânia: Pró-reitoria de Pesquisa e Inovação, 2015. Disponível em: https://www.ufg.br/n/85121-iniciacao-cientifica. Acesso em: 06 set. 2019.

KALANTZIS, M.; COPE, B. Changing the role of schools. In: COPE, B.; KALANTZIS, M. (Eds). Multiliteracies- Literacy Learning and the design of social futures. New York: Routledge, 2006, p. 121-148. 
VALENIA, A.

KALANTZIS, M.; COPE, B.; HARVEY. Assessing multiliteracies and the newbasics. Assessment in Education, 10(1), 2003.

KATO, M. No mundo da escrita: uma perspectiva psicolinguística. São Paulo: Ática, 1986.

LEMLE, M. Guia teórico do alfabetizador. São Paulo: Ática, 1995.

MOITA-LOPES, L. P.; ROJO, R. H. R. Linguagens, códigos e suas tecnologias. In: BRASIL/MEC/SEB/DPEM. Orientações curriculares de ensino médio. Brasília, DF: MEC/SEB/DPEM, 2004. Disponível em: http://portal.mec.gov.br/seb/arquivos/pdf/02Linguagens.pdf. Acesso em: 03 set. 2019.

MYERS, J.; HAMMETT, R.; McKILLOP, A. M. Opportunities for critical literacy and pedagogy in student-authored hypermedia. In: REINKING, D. et al. Handbook of literacy and technology: transformations in a post-typographic world. New Jersey: Lawrence Erlbaum Associates, 1998, p. 63-78.

ROJO, R.; MOURA, E. Multiletramentos na escola. São Paulo: Parábola Editorial, 2012.

ROJO, R. H. R. Letramentos múltiplos, escola e inclusão social. São Paulo: Parábola Editorial, 2009. ROJO, R. H. R. Gêneros do discurso e gêneros textuais: questões teóricas e aplicadas. In: MEURER, J. L.; ADAIR, B. MOTTA-ROTH, D. Gêneros: teoria, métodos, debates. São Paulo: Parábola Editorial, 2001, p. 184-207.

ROJO, R. H. R. Modos de transposição dos PCNs às práticas de sala de aula: progressão curricular e projetos. In: ROJO, R. H. R. A prática de linguagem em sala de aula: praticando os PCNs. Campinas: Mercado de Letras, 2000, p. 27-40.

SANTOS, T. C. dos; DIAS, A. V. M. O hiperconto digital como objeto de ensino de língua materna. In: 3ํㅡㄹ Congresso de Pesquisa, ensino, Extensão e Cultura - CONPEEX, 3ํ, 2017, Goiânia-GO. Anais do 3ํㅡㄹ Congresso de Pesquisa, ensino, Extensão e Cultura. Goiânia-GO, 2017, v. 02, p. 12941299. Disponível em https://iiiconpeex.catalao.ufg.br/up/957/o/mostra_prolicen.pdf?1508686015. Acesso em: 07 set. 2019.

SMOLKA, A. L. B. A criança na faze inicial da escrita: a alfabetização como processo discursivo. São Paulo: Cortez; Campinas: Editora da Universidade Estadual de Campinas, 2003 (Coleção passando a limpo).

SOARES, M. Letramento: um tema em três gêneros. Belo Horizonte: Autêntica, 2006.

SOARES, M. Novas práticas de leitura e escrita: letramento na cibercultura. Revista Educação e Sociedade, Campinas, v. 23, n. 81, 2002, p. 143-160.

SOUZA-SANTOS, B. de. Os processos da globalização. In: SOUZA-SANTOS, B. de (Org.). A globalização e as ciências sociais. São Paulo: Cortez, 2005, p. 25-102.

SOUZA-SANTOS, B. de. Poderá o direito ser emancipatório? Revista Crítica de Ciências Sociais, 65, maio de 2003, p. 3-76. Disponível em: http://www.boaventuradesousasantos.pt/media/pdfs/podera_o_direito_ser_emancipatorio_RCCS6 5.PDF. Acesso em: 06 set. 2019. 
VALENIA, A.

STREET, B. V. What's "new" in new literacy studies? Critical approaches to literacy in theory and practice. Current Issues in Comparative Education, Columbia, v. 5, n. 2, p. 77-91, 2003. Disponível em: http://www.tc.columbia.edu/cice/lssues/05.02/52street.pdf. Acesso em: 02 set. 2019.

XAVIER, A. C. S. Letramento digital e ensino. 2009. Disponível em: http://www.ufpe.br/nehte/artigos/Letramento\%20digital\%20e\%20ensino.pdf. Acesso em: 02 set. 2019.

Como citar este artigo (ABNT)

VALENIA, A. Linguagem e tecnologia na formação de professores de língua. SELL, Uberaba, MG, v. X, n. X, p. XXX-XXX, 2019. Disponível em: <inserir link de acesso >. Acesso em: inserir dia, mês e ano de acesso. DOI: inserir link do DOI.

Como citar este artigo (APA)

VALENIA, A. (2019). Linguagem e tecnologia na formação de professores de língua. SELL, X(X), XXX-XXX. Recuperado em: inserir dia, mês e ano de acesso de inserir link de acesso. DOI: inserir link do DOI. 